Experimental study and validation of a kinetic scheme for Hydrothermal Carbonization reactions

Fidel Vallejo*, Luis A. Diaz-Robles, Jorge Poblete, Francisco Cubillos

Departamento de Ingeniería Química, Universidad de Santiago de Chile, Libertador Bernardo O’Higgins 3363, Estación Central, Chile

Programa Centro de Valorización de Residuos y Economía Circular, Chile

* fidel.vallejo@usach.cl - https://orcid.org/0000-0001-5835-298X

\title{
Acknowledgments
}

This work has been founded by Projects FONDEF ID18I10182 and BMBF-CONICYT 150067.

F. Vallejo acknowledges the support of the Conicyt National Doctorate Grant Folio 21170340. 


\section{Experimental study and validation of a kinetic scheme for Hydrothermal Carbonization reactions}

\section{Abstract}

This study presents a new kinetic scheme for the mass yield prediction of waste lignocellulosic biomasses treated by Hydrothermal Carbonization (HTC). The proposed reactions are based on the decomposition, solubilization, and polymerization of each main fraction of the biomass: cellulose, hemicellulose, and lignin. The ash content was assumed to be inert. The kinetic parameters have been obtained by non-linear adjustment using a data set with 220 experimental runs collected from the literature. The results indicate that the pre-exponential factors range was from $7.33 \times 10^{1}$ to $1.412 \times 10^{5} \mathrm{~min}^{-1}$, and activation energies were between 33.75 y $225.3 \mathrm{~kJ} / \mathrm{mol}$. A good fit is achieved between the observed and predicted data with an $\mathrm{R}^{2}$ of 0.81 and an RMSE of $7.7 \%$. The proposed scheme was validated with the experimental data obtained by the HTC of sawdust (Pinus radiata) and rapeseed (Brassica napus). The experiments were carried out at temperatures of 190,220 , and $250{ }^{\circ} \mathrm{C}$ and reaction times of $0,30,60,90$, and $120 \mathrm{~min}$. The predicted values showed an average error of 2.3 and $3.5 \%$, respectively. Therefore, the kinetic scheme is a useful tool in the conversion analysis of waste biomass treated by HTC.

\section{Graphical abstract}

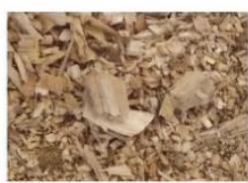

Biomass Subcritical water
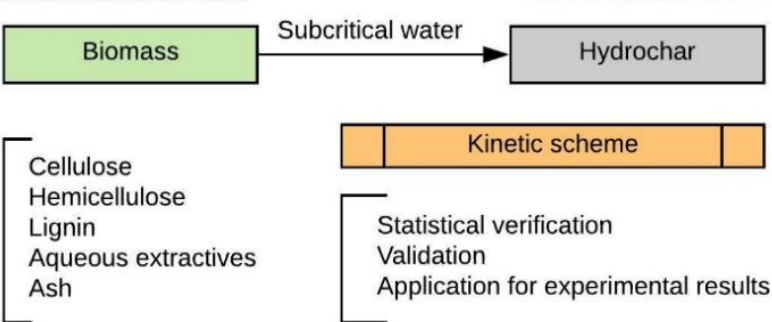

Validated kinetic scheme. A general model based on the Arrhenius equation for the decomposition of each main fraction of lignocellulosic biomass has been proposed, adjusted with literature data, validated, and applied to experimental results of residual biomass. The results show a suitable adjustment of the predicted values, with an average error of $2-3 \%$ and a maximum of $6 \%$.

Keywords: hydrothermal carbonization, lignocellulosic biomass, reaction kinetic, nonlinear regression model, waste-to-energy 


\section{Introduction}

Hydrothermal carbonization (HTC) is used for the waste biomass conversion into a solid product (hydrochar), obtaining an increase in the carbon content ${ }^{[1]}$ and the higher calorific value $^{[2]}$. Prior studies have shown other advantages of hydrochar, such as hydrophobic properties ${ }^{[3]}$ and a lower ash content ${ }^{[4]}$. Currently, the hydrochar is used as a biofuel in boilers and stoves ${ }^{[5]}$, as a precursor of activated carbon ${ }^{[6]}$, catalysts ${ }^{[7]}$, capacitors, among others ${ }^{[8,9]}$. The HTC has been deeply studied in some key areas, such as maximize the energy yield by analyzing the influence of the operating parameters and type of biomass treated ${ }^{[10-13]}$ and the study of elemental and complex kinetics for specific biomasses ${ }^{[14-17]}$. Besides, economic and feasibility analysis have been carried out to scale the process in batch and continuous pilot plants ${ }^{[18-20]}$ and to evaluate the environmental impact ${ }^{[21]}$. However, the process must overcome a few challenges as high costs of process equipment, mainly the reactor, due to inadequate knowledge of the reaction mechanism and biomass kinetic during carbonization ${ }^{[19]}$.

Several previous works have studied HTC kinetic and reaction mechanisms making specific assumptions for each biomass. Therefore, the results are only applicable in limited cases since this model was not compared with others nor applied to different raw biomass. Knezevic et al. (2009) analyzed HTC of pure glucose and then extrapolated the results to two other lignocellulosic biomasses. One of the main findings was that there were no significant changes in the $\mathrm{H} / \mathrm{C}$ and $\mathrm{O} / \mathrm{C}$ ratios after 5 minutes of residence, with a significant decrease in the hydrogen and oxygen contents ${ }^{[22,23]}$. This reduction generates an increase in the hydrochar calorific value as oxygen content is higher than in other solid fuels. Higher heating value (HHV) of the final product reaches $30-33 \mathrm{MJ} / \mathrm{kg}$, while the raw biomass HHV is between $18.5-21$ $\mathrm{MJ} / \mathrm{kg}{ }^{[22,24,25]}$. Another issue to evaluate is the significant presence of volatile matter (70 $85 \%)$ in biomass, a higher value than traditional coal (35-50\%); consequently, biomass is more reactive ${ }^{[24]}$. On the other hand, the primary way to eliminate the amount of oxygen present 
in biomass is due to two exothermic reactions: dehydration and decarboxylation ${ }^{[26,27]}$. An increase in reaction time causes the biomass to move along the paths of these reactions in all cases considered ${ }^{[28]}$.

Some studies have been developed to get a valid model to describe the biomass conversion in hydrochar evaluating mass yield (MY) and HHV, mainly linear regression models ${ }^{[12,13,29]}$. On the other hand, there is no general kinetic model for biomass available from the literature. Most studies in the field of HTC kinetic have only focused on elemental composition, i. e., carbon, oxygen, hydrogen, and nitrogen. However, some researchers have drawn attention to the very different behavior of elemental atoms (CHONS) inside of the biomass due to chemical and structural effects between lignin with cellulose and hemicellulose ${ }^{[15,30,31]}$. Therefore, this study aims to find a general kinetic scheme to describe the biomass changes during the HTC process as a function of the main fractions, i. e., cellulose, hemicellulose, and lignin. The data indicate a wide variety of biomass composition, as shown in Table $\mathbf{1 .}$

Here: Table 1

In the same way, Table 2 shows a summary of the main kinetic parameters for the lignocellulosic biomass fractions. It has been reported that at $200{ }^{\circ} \mathrm{C}$, water degrades hemicellulose in furfurans and other compounds ${ }^{[32]}$. According to the study by Reza et al. (2013) ${ }^{[17]}$ that evaluated the HTC process with different biomasses, there was no evidence that hemicellulose exists in the product at temperatures above $230^{\circ} \mathrm{C}$. On the other hand, cellulose requires more energetic conditions to break the glycosidic bonds, usually acidified medium and high temperatures ${ }^{[17]}$. Cellulose degrades into oligomers, a part of them is hydrolyzed to form glucose, and the rest remains as an interlaced polymer ${ }^{[30]}$. The findings of this study indicated that at $200{ }^{\circ} \mathrm{C}$, there was an increase in the amount of cellulose due to the elimination of 
hemicellulose with values above $90 \%$ at $34,5 \mathrm{MPa}$ and $200-230{ }^{\circ} \mathrm{C}$. Although the lignin fraction solubilization started at $200{ }^{\circ} \mathrm{C}$, there was no significant degradation until the temperature reaches $260-280{ }^{\circ} \mathrm{C}$, causing a net increment of lignin content, which in some cases such as Pinus radiata was about three times the initial value ${ }^{[24,27,30]}$.

Here: Table 2

Finally, the activation energies of hemicellulose degradation are between $82-156 \mathrm{~kJ} / \mathrm{mol}$ for several studied cases in a temperature range of $145-190{ }^{\circ} \mathrm{C}$ considering first-order reactions

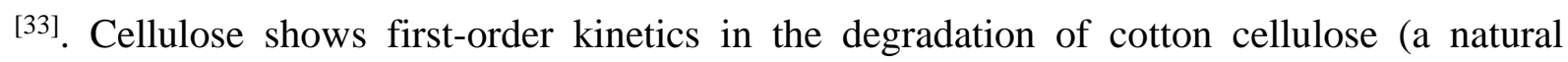
compound with the highest amount cellulose) with an activation energy of $129 \mathrm{~kJ} / \mathrm{mol}$ at temperatures of $215-274{ }^{\circ} \mathrm{C}{ }^{[34,35]}$. Other authors have found a value of $215 \mathrm{~kJ} / \mathrm{mol}$ at 210 $370{ }^{\circ} \mathrm{C}$. Although the lignin content is usually assumed as inert, some authors did not use this assumption ${ }^{[36]}$. The studies have been developed mainly for temperatures much higher than the nominal range of $\mathrm{HTC}\left(180-280^{\circ} \mathrm{C}\right)$, as in the study by Zhang et al. (2007) that determined activation energies of $37-46 \mathrm{~kJ} / \mathrm{mol}$ at $300-374{ }^{\circ} \mathrm{C}{ }^{[25]}$.

\section{Methods}

\subsection{Data collection}

This study was conducted by data collection from literature to obtain the kinetic parameters for the proposed reaction scheme by nonlinear regression and its validation with experimental runs for two Chilean lignocellulosic biomasses. The first part was carried out with a set of 220 experimental runs, about 50 lignocellulosic biomasses, recollected from the literature. The proposed kinetic scheme for this work is indicated in Figure 1. Aqueous extractives (AE) and hemicellulose $(\mathrm{H})$ generate only soluble products, while cellulose (C) and lignin (L) 
decomposition produce a soluble part (liquid and gas phases) and a solid by polymerization $[17,37]$.

Here: Figure 1

The reaction of each biomass fraction was described in the kinetic and differential form. The solution was determined by integration of the differential equations with an initial mass at time zero. It was assumed that AE goes out of the biomass completely at a temperature above $180^{\circ}$ C, and all reactions were first-order, as shown in Table 3 .

The parameters $\mathrm{k}_{0}, \mathrm{k}_{1}, \mathrm{k}_{2}, \mathrm{k}_{3}, \mathrm{k}_{4}$, and $\mathrm{k}_{5}$, are the first-order kinetic constants. $\mathrm{X}_{\mathrm{A}}(\mathrm{t})$ and $\mathrm{A}_{0}$ are the ash contents at any time and initial time in the hydrochar, respectively. The pre-exponential factor and activation energy were determined for each constant by the Arrhenius relation, as shown in Equation 1.

$k_{i}=A_{i} e^{\frac{-E A_{i}}{R T}}$, for $i=1,2, \ldots, 5$

R Software (nlm and faraway packages) ${ }^{[38,39]}$ and Excel VBA were used to solve the equation system. The graphics were obtained by ggplot2 [40]

Here: Table 3

\subsection{Hydrothermal Carbonization}

HTC experiments were carried out to evaluate the model performance. Radiata pine sawdust (AS) and rapeseed (RPS) were collected in southern Chile during the year 2018, and they were stored and used as received in the experiments. Moisture (M) was determined with the 
gravimetric method ${ }^{[41]}$, and HHV was carried out in a Parr 6200 calorimeter (Parr Instruments, USA). Proximate analysis was performed by the Van Soest method ${ }^{[11]}$ of NDF-ADF-ADL (neutral detergent fiber, acid detergent fiber, and acid detergent lignin), where the components calculated were the ash, lignin, cellulose, hemicellulose and aqueous extractives (A, L, C, H, and AE, respectively). Finally, C, O, H, and $\mathrm{N}$ mass fractions of AS and RPS were analyzed. Table 4 shows the results.

Here: Table 4

Hydrothermal carbonization experiments were performed in a high-pressure reactor, model HiPR-SF5L, with a volume capacity of $5 \mathrm{~L}$. The detailed description of the process can be found in previous works of this research group ${ }^{[3,11]}$. For the kinetic study, fifteen experimental runs for each biomass were carried out with a biomass - water ratio (B/W) equal to 0.10 . A dry biomass amount of $300 \mathrm{~g}$ in each experiment was used. The temperatures analyzed were 190, 220, and $250^{\circ} \mathrm{C}$ with five reaction times: $0,30,60,90$, and $120 \mathrm{~min}$.

\section{Results and discussion}

\subsection{Kinetic parameters determination}

A routine was developed in Excel VBA and R-Project 3.5.3 for the determination of the kinetic parameters that generated the best fit for the experimental data, measured with the Root Mean Squared Error (RMSE) and the coefficient of determination $\left(\mathrm{R}^{2}\right)$. The set of initial values were taken from the literature ${ }^{[17,37]}$. The values of each constant are indicated in Table 5. Although the model and the assumptions used prevent the direct comparison of values obtained with other models, the order of magnitude of the activation energies, between 33.75 to $225.3 \mathrm{~kJ} / \mathrm{mol}$, was like values reported by Reza et al. (2013): 29 and $77 \mathrm{~kJ} / \mathrm{mol}$ for hemicellulose and cellulose, respectively ${ }^{[17]}$. On the other hand, the pre-exponential factors were in the same order of 
magnitude than parameters obtained by schemes applied to wood pyrolysis ${ }^{[37]}$. The Activation Energies reported in previous studies were higher than for this investigation, this difference can be explained by an increase in biomass reactivity due to the solubilization of the aqueous extractives fraction in the bulk liquid, and the decrease in $\mathrm{pH}$ generated in the early stages of the reaction ${ }^{[30]}$. The main difference found was the activation energy of lignin, which, according to this proposed scheme, was higher than that determined by Zhang et al. (2007), probably because the very different temperature range considered ${ }^{[25]}$. Besides, the activation energy for hemicellulose reaction $\left(\mathrm{EA}_{1}\right)$ was much lower than the activation energy of cellulose $\left(\mathrm{EA}_{2}, \mathrm{EA}_{3}\right)$ and lignin reactions $\left(\mathrm{EA}_{4}, \mathrm{EA}_{5}\right)$, because hemicellulose requires a lower process temperature to complete solubilization, i. e., its decomposition was reached faster. Several studies carried out with TGA have shown the order of decomposition of the biomass components when the reaction temperature increases: hemicellulose - cellulose - lignin ${ }^{[3]}$. While the physical significance of Arrhenius constants for heterogeneous reactions has not been clearly defined, comparing the order of magnitude of activation energies suggests that the model is consistent with the actual process and with the observations made in some studies ${ }^{[17,24]}$.

\section{Here: Table 5}

The comparison between predicted and observed values indicated an $\mathrm{R}^{2}$ of 0.81 with an RMSE of $7.7 \%$, as shown in Figure 2 A. In the same way, the residuals presented a normal distribution by applying the Shapiro Test. A p-value of 0.49 implies that the null hypothesis cannot be rejected. The standardized residuals against the theoretical quantiles are presented in Figure 2 B. Therefore, the proposed kinetic scheme shows a good fit and explains the decomposition of the initial solid during the process and its transformation into hydrochar. 


\subsection{Case studies results}

The results of sawdust HTC showed that at $190^{\circ} \mathrm{C}$, the MY decreases from $98.7 \%$ for a reaction time of $0 \mathrm{~min}$, to $74.8 \%$ for 120 minutes. This difference was due to the AE initial $\left(\mathrm{AE}_{0}\right)$ was solubilized $\left(\mathrm{AS}-\mathrm{AE}_{0}=2.79 \%\right)$, and there was a partial degradation of hemicellulose $\left(\mathrm{H}_{0}=25 \%\right)$, which increased with the reaction time. At $220^{\circ} \mathrm{C}$, MY changed from 77.9 to $70.6 \%$ between 0 and 120 min, respectively, due to the partial conversion of cellulose $\left(\mathrm{C}_{0}=\right.$ $42 \%$ ) into hydrochar. Something similar can be observed for $250{ }^{\circ} \mathrm{C}$, with values between 66.5 and $55.3 \%$.

On the other hand, RPS had a different composition, with lower initial cellulose and lignin content, 23 and $15 \%$, respectively, and a higher fraction of aqueous extractives (44.6\%). At $190{ }^{\circ} \mathrm{C}$, the values were between 59.7 and $42.2 \%$ for 0 and $120 \mathrm{~min}$, respectively, while at $250{ }^{\circ} \mathrm{C}$, the MY obtained for 120 min was $36.5 \%$. As Table 6 shows, the model developed performance in this work for both Chilean biomasses indicates a good fit for the predicted values with an $\mathrm{R}^{2}$ of 0.81 with an RMSE of $4.3 \%$.

Here: Table 6

As proposed in the kinetic scheme, the AE fraction is wholly removed from the raw biomass above $180^{\circ} \mathrm{C}$. Indeed, under the same conditions of temperature and time, the mass yield of the sawdust was higher than the rapeseed due to the difference in the AE content: AS, $2.79 \%$, and RPS, $44.6 \%$. Furthermore, sawdust has a higher lignin content, which starts to react above 260 ${ }^{\circ} \mathrm{C}$, a higher value than the range studied. Consequently, the MY average for the RPS was significantly lower. 
On the other hand, no significant differences were found between the $\mathrm{R}^{2}$ and RMSE showed in the previous subsection ( 0.81 and $4.3 \%$, respectively) and the reported values by earlier studies with models to predict MY in specific biomasses ${ }^{[14,42]}$ and blends ${ }^{[11]}$. Indeed, the equations for MY obtained by Multiple Linear Regression and Regression Trees ${ }^{[13]}$ indicated an $\mathrm{R}^{2}$ of 0.85 and an RMSE of $6 \%$. The proposed kinetic model presented an average error with the validation data set of 2.3 and $3.5 \%$ for sawdust and raps, respectively. The experimental values obtained for the mass yield were similar to those reported in the literature ${ }^{[10,11,17]}$, allowing to validate the direct correlation between the macromolecular composition and the behavior of the biomass during the HTC process.

\section{Conclusions}

This work presents a novel kinetic scheme to describe the behavior of lignocellulosic biomass during the Hydrothermal Carbonization (HTC) process. The kinetic parameters were determined by a non-linear regression for Arrhenius reactions with 220 experimental runs collected from the literature. Although a direct comparison for the values obtained for the kinetic constants was not possible, an agreement in the order of magnitude was shown with models that describe the pyrolysis of lignocellulosic biomasses. The predicted values showed a determination coefficient $\left(\mathrm{R}^{2}\right)$ of 0.81 with an RMSE of $7.7 \%$. Finally, the model developed was applied to experimental results, showing an average error of 2.3 and $3.5 \%$ for sawdust and rapeseed, respectively, with a maximum value of $6 \%$ for both biomasses. These results underlined the importance of studying the macromolecular composition to predict the MY during the HTC process. A direct implication of the results obtained is the need to consider indepth the decomposition reactions of cellulose and hemicellulose. Both fractions are removed from the raw biomass in the temperature range of 180 to $250^{\circ} \mathrm{C}$.

\section{Declaration of interest statement}

The authors declare that they have no conflicts of interest 


\section{References}

[1] M. Volpe, J. L. Goldfarb, L. Fiori, Bioresour. Technol. 2018, 247, 310-318.

[2] I. Oliveira, D. Blöhse, H.-G. Ramke, Bioresour. Technol. 2013, 142, 138-146.

[3] E. Monedero, M. Lapuerta, A. Pazo, L. A. Díaz-Robles, E. Pino-Cortés, V. Campos, F. Vallejo, F. Cubillos, J. Gómez, Biomass and Bioenergy 2019, 130, 105387.

[4] A. M. Smith, S. Singh, A. B. Ross, Fuel 2016, 169, 135-145.

[5] M. Shirai, M. Osada, A. Yamaguchi, N. Hiyoshi, O. Sato, Recent Advances in ThermoChemical Conversion of Biomass, 2015.

[6] B. Zhang, M. Heidari, B. Regmi, S. Salaudeen, P. Arku, M. Thimmannagari, A. Dutta, Energies 2018, 11, 2022-2035.

[7] F. Safari, N. Javani, Z. Yumurtaci, Int. J. Hydrogen Energy 2018, DOI 10.1016/j.ijhydene.2017.05.102.

[8] A. Jain, R. Balasubramanian, M. P. Srinivasan, Chem. Eng. J. 2016, 283, 789-805.

[9] S. Zhang, X. Zhu, S. Zhou, H. Shang, J. Luo, D. C. W. Tsang, in Biochar from Biomass Waste, 2019.

[10] J. G. Lynam, M. T. Reza, W. Yan, V. R. Vásquez, C. J. Coronella, Biomass Convers. Biorefinery 2015, 5, 173-181.

[11] F. Vallejo, L. A. Diaz-Robles, F. Cubillos, R. Vega, E. Pino-Cortés, S. Carrasco, J. Gomez, Chem. Eng. Trans. 2019, 76, 1453-1458.

[12] L. Li, J. R. V. Flora, J. M. Caicedo, N. D. Berge, Bioresour. Technol. 2015, 187, $263-$ 274.

[13] F. Vallejo, L. A. Diaz-Robles, R. Vega, F. Cubillos, J. Energy Inst. 2020.

[14] D. Basso, E. Weiss-Hortala, F. Patuzzi, M. Baratieri, L. Fiori, Energies 2018, 11, 1379.

[15] D. Jung, A. Kruse, J. Anal. Appl. Pyrolysis 2017, 127, 286-291.

[16] M. Lucian, G. Piro, L. Fiori, Chem. Eng. Trans. 2018, 65, 379-384.

[17] M. T. Reza, W. Yan, M. H. Uddin, J. G. Lynam, S. K. Hoekman, C. J. Coronella, V. R. Vásquez, Bioresour. Technol. 2013, 139, 161-169.

[18] S. K. Hoekman, A. Broch, L. Felix, W. Farthing, Energy Convers. Manag. 2017, 134, 247-259.

[19] M. Lucian, L. Fiori, Energies 2017, 10, 211-215.

[20] P. McKendry, Bioresour. Technol. 2002, 83, 47-54.

[21] V. Benavente, A. Fullana, N. D. Berge, J. Clean. Prod. 2017, 142, 2637-2648.

[22] D. Knežević, W. P. M. van Swaaij, S. R. A. Kersten, Ind. Eng. Chem. Res. 2009, 48, 4731-4743.

[23] D. Knežević, W. van Swaaij, S. Kersten, Ind. Eng. Chem. Res. 2010, 49, 104-112.

[24] A. Y. Krylova, V. M. Zaitchenko, Solid Fuel Chem. 2018, 52, 91-103.

[25] R. Zhang, H. M. El-Mashad, K. Hartman, F. Wang, G. Liu, C. Choate, P. Gamble, Bioresour. Technol. 2007, 98, 929-935.

[26] A. Funke, F. Ziegler, Biofuels, Bioprod. Biorefining 2010, 4, 160-177.

[27] A. A. Peterson, F. Vogel, R. P. Lachance, M. Fröling, M. J. Antal, Jr., J. W. Tester, Energy Environ. Sci. 2008, 1, 32.

[28] X. Lu, N. D. Berge, Bioresour. Technol. 2014, 166, 120-131.

[29] K. S. Ro, J. R. V. Flora, S. Bae, J. A. Libra, N. D. Berge, A. Álvarez-Murillo, L. Li, ACS Sustain. Chem. Eng. 2017, 5, 7317-7324.

[30] T. Wang, Y. Zhai, Y. Zhu, C. Li, G. Zeng, Renew. Sustain. Energy Rev. 2018, 90, 223247.

[31] M. Toufiq Reza, B. Wirth, U. Lüder, M. Werner, Bioresour. Technol. 2014, 169, 352361.

[32] K. Tekin, S. Karagöz, S. Bektaş, Renew. Sustain. Energy Rev. 2014, 40, 673-687.

[33] G. Garrote, H. Domínguez, J. C. Parajó, Holz als Roh- und Werkst. 1999, 57, 191-202. 
[34] O. Bobleter, Prog. Polym. Sci. 1994, 19, 797-841.

[35] W. Schwald, O. Bobleter, J. Carbohydr. Chem. 1989, 8, 565-578.

[36] M. Jatzwauck, A. Schumpe, Biomass and Bioenergy 2015, 75, 94-100.

[37] P. Ahuja, S. Kumar, P. C. Singh, Chem. Eng. Technol. 1996, 19, 272-282.

[38] R Core Team, 2019.

[39] J. Faraway, Linear Models with R, CRC Press, Boca Raton, 2014.

[40] H. Wickham, Ggplot2: Elegant Graphics for Data Analysis, Springer-Verlag, New York, USA, 2016.

[41] International Organization for Standardization, Solid Biofuels. Determination of Moisture Content. Oven Dry Method. Part 2: Total Moisture. Simplified Method, 2017, UNE-EN ISO 18134-2.

[42] E. Sabio, A. Álvarez-Murillo, S. Román, B. Ledesma, Waste Manag. 2016, 47, 122132.

[43] E. Dinjus, A. Kruse, N. Tröger, Chem. Eng. Technol. 2011, 34, 2037-2043.

[44] S. Kieseler, Y. Neubauer, N. Zobel, Energy and Fuels 2013, 27, 908-918.

[45] J. Mumme, L. Eckervogt, J. Pielert, M. Diakité, F. Rupp, J. Kern, Bioresour. Technol. 2011, 102, 9255-9260.

[46] T. Adschiri, S. Hirose, R. Malaluan, K. Arai, J. Chem. Eng. JAPAN 1993, 26, 676-680.

[47] K. Mochidzuki, A. Sakoda, M. Suzuki, Thermochim. Acta 2000, 348, 69-76.

[48] M. Sasaki, T. Adschiri, K. Arai, AIChE J. 2004, 50, 192-202.

[49] Mitsuru Sasaki, Zhen Fang, Yoshiko Fukushima, T. Adschiri, K. Arai, Ind. Eng. Chem. Res 2000, 39, 2883-2890. 
Table 1. Composition of various lignocellulosic biomass

\begin{tabular}{ccccc}
\hline Biomass & Cellulose & Hemicellulose & Lignin & Ref \\
\hline Eucalyptus viminalis & 41.7 & 14.1 & 31.0 & {$[27]$} \\
Oak & 40.4 & 35.9 & 24.1 & {$[27]$} \\
Pinus radiata & $42-50$ & $24-27$ & 20 & {$[27]$} \\
Corncob & $33.7-41.2$ & $31.9-36$ & $6.1-15.9$ & {$[27]$} \\
Wheat straw & $32.9-50$ & $24-33.5$ & $8.9-17.3$ & {$[27]$} \\
Rice straw & $36.2-47$ & $19-24.5$ & $9.9-24$ & {$[27]$} \\
Vine sprouts & $35.6-38.3$ & $20.6-35.0$ & $22.8-23.4$ & {$[27]$} \\
Cauliflower & 70.0 & 11.0 & 10.0 & {$[43]$} \\
Grass & 45.0 & 41.0 & 4.0 & {$[43]$} \\
Beechwood & 59.0 & 22.0 & 18.0 & {$[43]$} \\
Wheat stalk & 40.0 & 28.0 & 17.0 & {$[44]$} \\
Digestate maize silage & 26.0 & 1.0 & 38.0 & {$[45]$}
\end{tabular}


Table 2. Kinetic parameters for main biomass fractions

\begin{tabular}{|c|c|c|c|c|c|}
\hline Fraction $^{\text {a }}$ & $\begin{array}{l}\text { Temperature } \\
\left({ }^{\circ} \mathrm{C}\right)\end{array}$ & Reaction order & $\begin{array}{l}\text { Activation energy } \\
\qquad(\mathrm{kJ} / \mathrm{mol})\end{array}$ & Biomass & Ref \\
\hline \multirow{5}{*}{ C } & $215-274$ & Arrhenius, first-order & 129.1 & Cotton & [35] \\
\hline & $250-320$ & Arrhenius, first-order & 165 & Cellulose & [46] \\
\hline & $198-262$ & Arrhenius, first-order & 220 & Cellulose & [47] \\
\hline & $300-400$ & Arrhenius, first-order & $146-548$ & Microcrystalline cellulose & {$[48,49]$} \\
\hline & $210-370$ & Data fit by regression & 215 & Various & [27] \\
\hline $\mathrm{H}$ & $145-190$ & Arrhenius, first-order & $82-156$ & Various & [33] \\
\hline $\mathrm{L}$ & $300-374$ & Arrhenius, first-order & $37-46$ & Pure lignin and oatmeal hulls & [25] \\
\hline
\end{tabular}

(a) C: Cellulose, H: Hemicellulose, L: Lignin 
Table 3. Scheme kinetic for biomass fractions

\begin{tabular}{cccc}
\hline $\begin{array}{c}\text { Biomass } \\
\text { fraction }\end{array}$ & Kinetic & Differential & Solution \\
\hline Aqueous & equation & \\
extractives & $A E \rightarrow W$ & $\frac{d A E}{d t}=-k_{0}[A E]$ & $X_{A E}(t)=0, T>180{ }^{\circ} C$ \\
Hemicellulose & $H \rightarrow W$ & $\frac{d H}{d t}=-k_{1}[H]$ & $X_{H}(t)=H_{0} e^{-k_{1} t}$ \\
Cellulose & $C \rightarrow H_{C}$ & $\frac{d C}{d t}=-\left(k_{2}+k_{3}\right)[C]$ & $X_{H_{C}}(t)=C_{0} \frac{k_{2}}{k_{2}+k_{3}} e^{-\left(k_{2}+k_{3}\right) t}$ \\
Lignin & $C \rightarrow W$ & $X_{C}(t)=C_{0} e^{-\left(k_{2}+k_{3}\right) t}$ \\
& $L \rightarrow H_{L}$ & $\frac{d L}{d t}=-\left(k_{4}+k_{5}\right)[L]$ & $X_{L_{C}}(t)=L_{0} \frac{k_{4}}{k_{4}+k_{5}} e^{-\left(k_{2}+k_{3}\right) t}$ \\
Ash & $L \rightarrow W$ & & $X_{L}(t)=L_{0} e^{-\left(k_{4}+k_{5}\right) t}$ \\
Mass yield & & $M Y(t)=X_{H}(t)+X_{H_{C}}(t)+X_{C}(t)+X_{L_{C}}(t)+X_{L}(t)+X_{A}(t)$
\end{tabular}


Table 4. Raw biomass characterization

\begin{tabular}{|c|c|c|c|c|c|c|c|c|c|c|c|}
\hline \multirow{2}{*}{ Biomass } & \multirow{2}{*}{ M (\%) } & \multicolumn{5}{|c|}{ Proximate analysis } & \multirow{2}{*}{ HHV (MJ/kg) } & \multicolumn{4}{|c|}{ Ultimate analysis } \\
\hline & & $\mathrm{A}(\%)$ & $\mathrm{L}(\%)$ & C (\%) & $\mathrm{H}(\%)$ & $\mathrm{AE}(\%)$ & & $\mathrm{C}(\%)$ & $\mathrm{H}(\%)$ & $\mathrm{N}(\%)$ & $\mathrm{O}(\%)$ \\
\hline AS & 7.45 & 0.29 & 30.0 & 42.0 & 25.0 & 2.79 & 19.28 & 48.8 & 6.20 & 0.13 & 44.8 \\
\hline RPS & 7.32 & 7.37 & 15.0 & 23.0 & 10.0 & 44.6 & 21.36 & 49.7 & 6.85 & 5.30 & 30.8 \\
\hline
\end{tabular}


Table 5. Kinetic parameters for proposed scheme

\begin{tabular}{lll}
$\begin{array}{l}\text { Biomass fraction } \\
\text { reaction }\end{array}$ & $\begin{array}{l}\text { Pre-exponential Factor } \\
\left(\mathbf{m i n}^{-1}\right)\end{array}$ & $\begin{array}{l}\text { Activation Energy } \\
(\mathbf{k J} / \mathbf{m o l})\end{array}$ \\
\hline $\begin{array}{ll}\text { Hemicellulose } \\
\text { Cellulose }\end{array}$ & $\mathrm{A}_{1}=7.71 \times 10^{1}$ & $\mathrm{EA}_{1}=33.78$ \\
& $\mathrm{~A}_{2}=1.41 \times 10^{5}$ & $\mathrm{EA}_{2}=83.75$ \\
& $\mathrm{~A}_{3}=5.79 \times 10^{4}$ & $\mathrm{EA}_{3}=72.40$ \\
Lignin & $\mathrm{A}_{4}=1.62 \times 10^{4}$ & $\mathrm{EA}_{4}=150.1$ \\
& $\mathrm{~A}_{5}=1.10 \times 10^{4}$ & $\mathrm{EA}_{5}=225.3$
\end{tabular}


Table 6. Observed and predicted mass yields for sawdust and rapeseed

\begin{tabular}{|c|c|c|c|c|c|c|c|}
\hline \multirow{2}{*}{$\mathrm{T}\left({ }^{\circ} \mathrm{C}\right)$} & \multirow{2}{*}{$t(\min )$} & \multicolumn{3}{|c|}{ AS } & \multicolumn{3}{|c|}{ RPS } \\
\hline & & MY & pred MY & error & MY & pred MY & error \\
\hline \multirow{5}{*}{190} & 0 & $98.7 \%$ & $93.1 \%$ & $5.5 \%$ & $59.7 \%$ & $53.3 \%$ & $6.3 \%$ \\
\hline & 30 & $88.8 \%$ & $86.4 \%$ & $2.5 \%$ & $54.6 \%$ & $50.6 \%$ & $4.0 \%$ \\
\hline & 60 & 83.6 \% & $81.5 \%$ & $2.1 \%$ & $52.3 \%$ & $48.5 \%$ & $3.8 \%$ \\
\hline & 90 & $78.8 \%$ & $77.9 \%$ & $0.8 \%$ & $49.7 \%$ & $47.0 \%$ & $2.7 \%$ \\
\hline & 120 & $76.8 \%$ & $75.3 \%$ & $1.4 \%$ & $42.2 \%$ & $45.9 \%$ & $3.7 \%$ \\
\hline \multirow{5}{*}{220} & 0 & $77.9 \%$ & $80.6 \%$ & $2.7 \%$ & $54.7 \%$ & $48.3 \%$ & $6.4 \%$ \\
\hline & 30 & $74.3 \%$ & $75.3 \%$ & $1.0 \%$ & $49.4 \%$ & $46.0 \%$ & $3.4 \%$ \\
\hline & 60 & $73.2 \%$ & $71.7 \%$ & $1.5 \%$ & $47.2 \%$ & $44.3 \%$ & $2.9 \%$ \\
\hline & 90 & $71.7 \%$ & $69.2 \%$ & $2.5 \%$ & $46.5 \%$ & $43.1 \%$ & $3.3 \%$ \\
\hline & 120 & $70.6 \%$ & $67.3 \%$ & $3.3 \%$ & $44.2 \%$ & $42.1 \%$ & $2.1 \%$ \\
\hline \multirow{5}{*}{250} & 0 & $66.5 \%$ & $63.9 \%$ & $2.6 \%$ & $46.4 \%$ & $40.4 \%$ & $6.0 \%$ \\
\hline & 30 & $63.1 \%$ & $60.6 \%$ & $2.5 \%$ & $42.3 \%$ & $38.6 \%$ & $3.7 \%$ \\
\hline & 60 & $59.3 \%$ & $57.8 \%$ & $1.5 \%$ & $38.7 \%$ & $37.1 \%$ & $1.6 \%$ \\
\hline & 90 & $57.5 \%$ & $55.2 \%$ & $2.3 \%$ & $37.8 \%$ & $35.7 \%$ & $2.1 \%$ \\
\hline & 120 & $55.3 \%$ & $53.0 \%$ & $2.4 \%$ & $36.5 \%$ & $34.4 \%$ & $2.1 \%$ \\
\hline
\end{tabular}




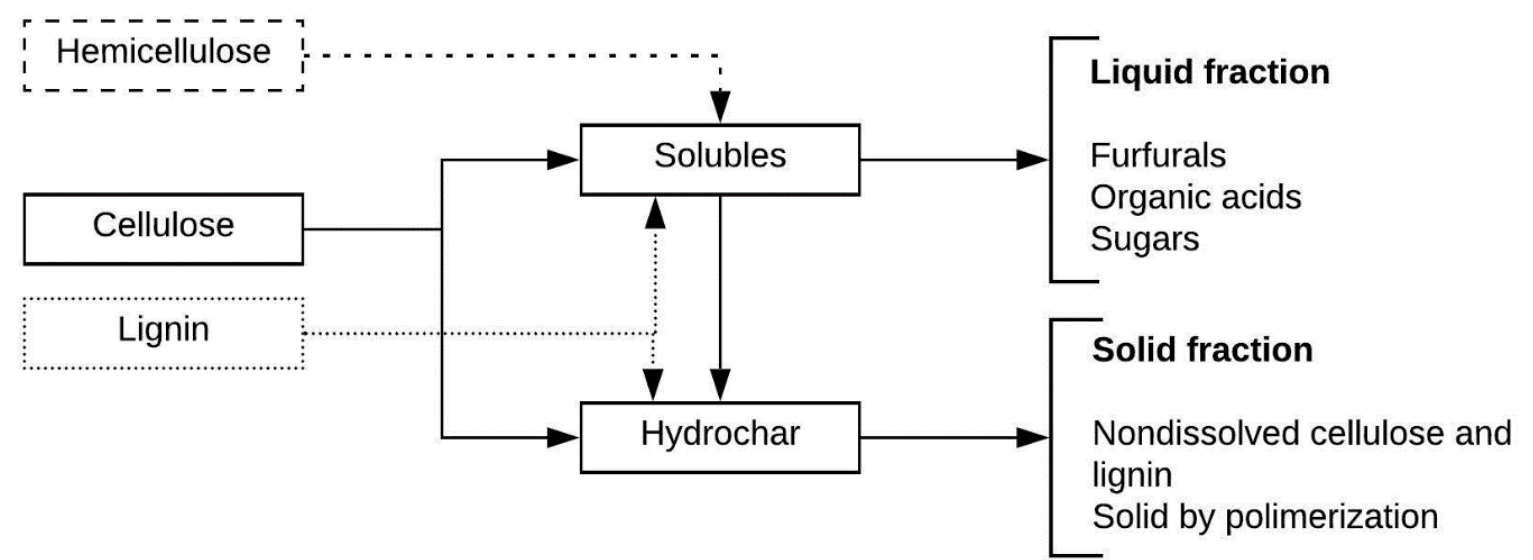

Figure 1. Kinetic scheme for biomass reactions to hydrochar

A

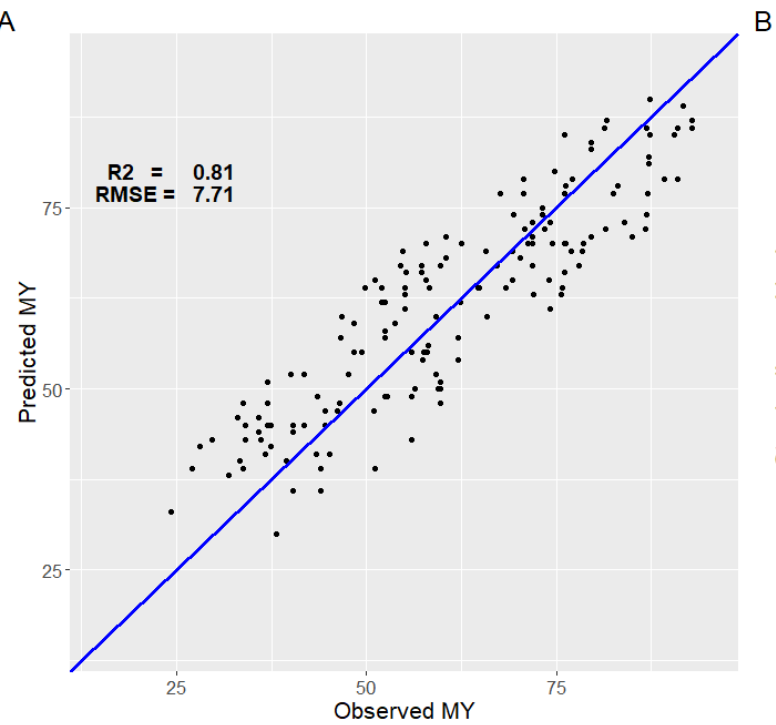

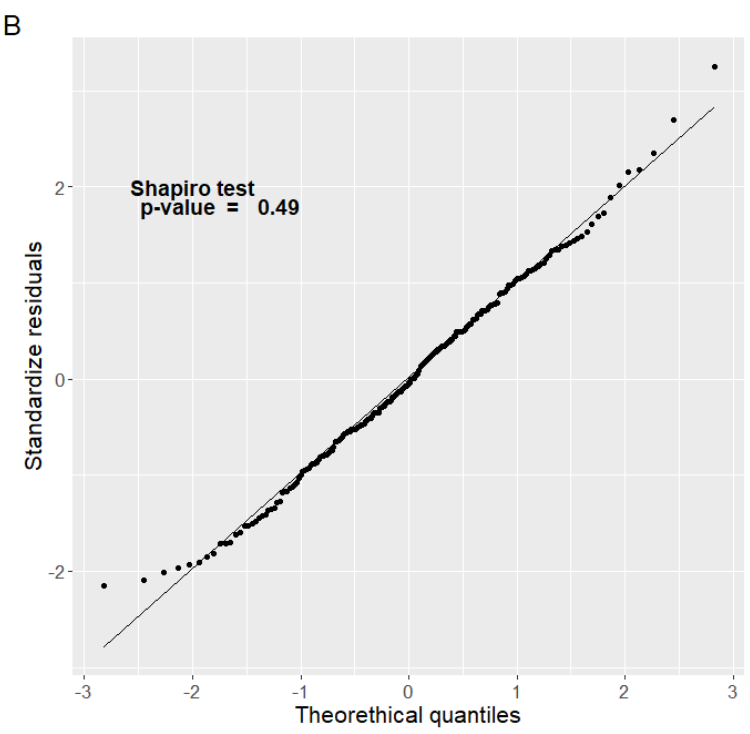

Figure 2. Observed and predicted mass yield values for the proposed kinetic model 
Figure Captions

Figure 1. Kinetic scheme for biomass reactions to hydrochar

Figure 2. Observed and predicted mass yield values for the proposed kinetic model 